\title{
Marketing Digital e o Comportamento de Compra do Consumidor: Um Panorama das Publicações e Proposição de Agenda de Pesquisa
}

\section{Digital Marketing and Consumer Buying Behavior: An Overview of Publications and Proposal of Research Agenda}

\author{
Weverson Soares Santos Mestrando em Administração. Universidade Federal de Santa Catarina (UFSC) - Brasil. \\ weverson_ss@hotmail.com \\ Martin de La Martiniere Petroll Doutor em Administração. Universidade Federal de Santa Catarina (UFSC) - Brasil. \\ martin.petroll@ufsc.br \\ João Henriques de Sousa Júnior Doutorando em Administração. Universidade Federal de Santa Catarina (UFSC) - Brasil. \\ sousajunioreu@hotmail.com \\ Rudimar Antunes da Rocha Doutor em Administração. Universidade Federal de Santa Catarina (UFSC) - Brasil. \\ rrudimar@hotmail.com
}

\begin{abstract}
RESUMO
Dados de mercado revelam crescimento no acesso à internet e na conectividade de pessoas e empresas. Neste contexto, o marketing digital tem sido incorporado nas estratégias de diversas empresas. Em face da importância do tema, buscou-se, neste estudo, através de uma pesquisa bibliométrica seguida de uma revisão sistemática integrativa, mapear a compreensão da influência do marketing digital no comportamento de compra dos consumidores e propor uma agenda de pesquisa acerca do tema. Para isto, foram avaliados artigos publicados nas bases de dados: Ebsco, Periódicos Capes, Scopus, Spell e Web of Science entre os anos de 2000 a 2019. Os resultados apontaram que mais de $60 \%$ das publicações foram realizadas entre os anos de 2016 e 2019 e que temas emergentes como "IOT", "economia compartilhada" e "marketing sensorial digital" são passiveis de melhor investigação. Estudos transculturais e longitudinais de temas como "influenciadores digitais" e "marketing boca a boca on-line" figuraram entre importantes gaps teóricos. Sugere-se estudos transculturais que permitam evidenciar características e gatilhos na utilização do marketing boca a boca digital, opção por modalidade de compra em grupo, opções por empresas com iniciativas sustentáveis e envolvendo a compra por impulso.
\end{abstract}

Palavras-chave: Marketing Digital. Comportamento de compra. Agenda de Pesquisa.

\section{ABSTRACT}

Market data reveal growth in internet access and in the connectivity of people and companies. In this context, digital marketing has been incorporated into the strategies of several companies. In view of the importance of the theme, this study is a bibliometric research followed by a systematic integrative review to understand the influence of digital marketing on consumers' purchasing behavior and propose a research agenda on the theme. For this, articles published in the databases: Ebsco, Periódicos Capes, Scopus, Spell and Web of Science between the years 2000 to 2019 were evaluated. The results showed that more than $60 \%$ of the publications were made between 2016 and 2019 and that emerging themes such as "IOT", "shared economy" and "digital sensory marketing" are emerging and need to be further explored. Cross-cultural and longitudinal studies on topics such as "digital influencers" and "on-line word of mouth marketing" were among important theoretical gaps. Cross-cultural studies are suggested to show characteristics and triggers in the use of digital word of mouth marketing, option for group purchase modality, options for companies with sustainable initiatives and involving impulse buying.

Keywords Digital marketing. Buying behavior. Research Agenda. 


\section{INTRODUÇÃO}

A discussão das mudanças trazidas pela internet às relações pessoais, interações sociais e, principalmente, no que se refere ao comportamento de compra, esteve no centro das discussões acadêmicas de pesquisadores de marketing e comportamento do consumidor na última década e ainda há muitas lacunas e questões a serem estudadas e respondidas acerca da temática do marketing digital e suas influências no comportamento de compra dos consumidores (CHIANG; YI LIN; HUANG, 2018; PETIT; VELASCO; SPENCE, 2019).

Um relatório publicado pelo We Are Social (2020), aponta que em janeiro de 2020, o Brasil contava com 150,4 milhões de usuários de internet e 140 milhões de usuários de mídias sociais. A média diária de uso da internet, entre os brasileiros, é de $9 \mathrm{~h} 17$ min por usuário, em janeiro de 2020 havia 205,8 milhões de conexões em dispositivos móveis, o número é equivalente a $97 \%$ de toda a população brasileira (WE ARE SOCIAL, 2020).

Os dados apresentados pelo We Are Social (2020) demonstram que os consumidores estão conectados à internet, por um longo período, e as empresas precisam adaptar-se cada vez mais a esse cenário. Nessa perspectiva, a Resultados Digitais (RD), empresa focado em ferramentas de marketing digital, realizou em 2019 uma pesquisa de mercado com o propósito de identificar a maturidade do marketing digital e vendas no Brasil (VOLPATO, 2019). A pesquisa obteve a participação de 1400 empresas, dentre elas, $94 \%$ afirmaram que já estão utilizando estratégias de marketing digital para alavancar seu crescimento, $91,1 \%$ possuem perfis nas redes sociais, $85,7 \%$ possuem sites próprios, $40 \%$ delas reconhecem que suas estratégias digitais geram demanda e $60 \%$ das empresas participantes reconhecem a necessidade de melhorar sua geração de conteúdo para melhor alcançar seu público alvo (VOLPATO, 2019).

Na perspectiva científica, a literatura revela que alguns segmentos foram forçados a digitalizar-se pela mudança nos hábitos de consumo (GONÇALVES et al., 2019). Enquanto outros encontraram na digitalização uma possibilidade de otimizar e potencializar seus lucros por meio do uso de plataformas digitais, o fato é que o marketing digital passou fazer parte das prioridades das empresas (KAPLAN; HAENLEIN, 2010; GOMES; REIS, 2015).

Por outro lado, os movimentos desse processo de digitalização tornaram-se cada vez mais dinâmicos e interativos, com impactos direto no comportamento de compra dos consumidores (KANNAN, 2017). Os consumidores passaram a desempenhar um papel relevante e ativo na geração de conteúdo, evidenciando seus hábitos e experiências e com muita interação entre pessoas jurídicas e pessoas físicas com dificuldades, em alguns momentos, de compreender quem é, de fato, o protagonista nesse processo de interação e integração digital (VARADARAJAN; YADAV, 2002; KANNAN, 2017).

Compreender e acompanhar as mudanças provocadas pelo marketing digital no comportamento de compras dos consumidores tornaram-se essenciais para as estratégias e planejamentos empresariais (RAMYA; ALI, 2016). Os consumidores passaram a envolver-se, em todo o processo de consumo, por fontes e canais interativos com alto envolvimento na geração de informações (CHIANG; YI LIN; HUANG, 2018). Esse comportamento revela um papel de completa oposição à mídia tradicional, uma vez que o controle da mensagem e do conteúdo não está mais restrito apenas ao profissional de marketing e este conteúdo possui forte influência no estímulo e na mudança do comportamento de compra dos consumidores (CHIANG; YI LIN; HUANG, 2018; SOUSA JÚNIOR, 2019).

Diante de todo esse cenário apresentado, esse trabalho possui por objetivo analisar as publicações nacionais e internacionais, indexadas nos principais bancos de dados de artigos científicos, acerca da influência do fenômeno do marketing digital no comportamento de compra dos consumidores.

\section{MARKETING DIGITAL E O COMPORTAMENTO DE COMPRA DO CONSUMIDOR}

A forma de fazer marketing por meio da internet e das plataformas digitais é denominado pela literatura em diferentes termos, dentre eles: on-line marketing, internet marketing, web marketing, marketing eletrônico, marketing digital e e-marketing (SURYAWARDANI; WIRANATHA, 2017). O termo marketing digital foi o que mais popularizou-se e tem sido a forma mais utilizada pelos pesquisadores e profissionais da área 
para abordar a temática. Dito isto, esclarece-se, neste ponto, que o presente trabalho também utilizará o termo marketing digital.

Nesse sentido, na busca por uma definição mais completa e robusta do termo, diversos autores buscaram dar suas contribuições ao longo dos anos. Coviello, Milley e Marcolin (2001) definiram o marketing digital como uma forma de estabelecer e mediar o diálogo por meio da internet a partir do uso de tecnologias e plataformas interativas. Anos depois, Mogos (2015) trouxe a definição de marketing digital na perspectiva da atração e obtenção de clientes através de serviços integrados e on-line. Por sua vez, mais tarde, Ryan (2017) definiu o marketing digital como um conjunto de atividades desenvolvidas com o propósito de promover e comercializar produtos por meio do uso de tecnologias e canais digitais. Frente ao exposto, esse artigo baseiase no conceito de marketing digital proposto por Ryan (2017).

Dentre as principais características do marketing digital destacam-se a capacidade aumentada de segmentação, praticidade e personalização da comunicação com maior velocidade e mais econômica que as ações tradicionais de promoção e comunicação (ALALWAN et al., 2017). Para além da comunicação e ações promocionais de cunho empresarial, a popularização da internet evidenciou uma nova categoria de conteúdos, àqueles gerados pelos usuários comuns da internet, comumente encontrado na literatura de língua inglesa como UGC (user-generated content)(KUMAR et al. 2016; ZHANG et al., 2018).

Discutir conteúdos gerados pelos usuários e o comportamento de compra exige tratar dos conteúdos relacionados a experiências de consumo, pois os consumidores com maior afinidade com interações no ambiente digital, tendem a fornecer feedbacks, indicações, recomendações e até contraindicações, sempre que podem, por meio dos diversos sites e mídias sociais (GREWAL; STEPHEN, 2019). A literatura classifica esse tipo de conteúdo como marketing boca a boca on-line (ou no inglês, WOM - Word of Mouth on-line) (SHAMOUT, 2016). Dentro dessa categoria encontra-se os comentários (reviews) on-line, reconhecido pelos consumidores como um conteúdo útil e de valor hedônico tanto na produção como em sua leitura, além de possuir grande influência no comportamento de compra em geral e na compra por impulso (SHAMOUT, 2016; GREWAL; STEPHEN, 2019).

A geração de conteúdos pelo consumidor, vai além do compartilhamento de experiências de consumo, há também a figura do ativismo digital, campanhas de boicote e alguns tipos de retaliações on-line, por parte de determinados grupos de consumidores (ALALWAN et al., 2017). Muitos autores classificam esse tipo de conteúdo como marketing boca a boca on-line negativo (ALGHARABAT et al., 2020). Este comportamento dos consumidores na internet torna ainda mais complexo o desafio enfrentado por empresas e profissionais de marketing que se propõem a atender as necessidades e desejos dos consumidores (RAMYA; ALI, 2016). A imprevisibilidade, avanço das tecnologias de comunicação, interações sociais cada vez mais intensas e rápidas compõe esse cenário de mudanças contínuas no comportamento de compra dos consumidores, tornando o tema vital para o sucesso no mercado (ALALWAN et al., 2017; ALGHARABAT et al., 2020).

É importante destacar que as novas tecnologias e plataformas digitais de interação social deram o acesso a esse universo de informações que provocam mudanças contínuas no comportamento das pessoas e especialmente no processo de escolha e compra de produtos, desde compras simples e rotineiras a compras mais complexas (MEYER-WAARDEN; BENAVENT, 2009; SIQUEIRA; ANGELO; ZWICKER, 2009; WATERLANDER et al., 2019). Uma pesquisa conduzida pelos pesquisadores Widodo, Yusiana e Anggi (2017) demonstrou que interações com marcas através das ferramentas de marketing digital são influenciadores determinantes do comportamento de compra dos consumidores. Na mesma perspectiva, o estudo de Moreno et al., (2017) apontou que consumidores da geração millenials são altamente conectados, tendem a interagir com marcas ligadas à sua identidade e possuem comportamento de compra altamente influenciado por pares e por promoções digitais, como a conquista de cupons eletrônicos.

Outras características inerentes ao comportamento do consumidor, como a impulsividade, são também alimentadas e estimuladas pelo ambiente digital e influenciam diretamente no comportamento de compra (ZHANG et al., 2018). Alguns pesquisadores destacam que consumidores que interagem em plataformas de mídias sociais são mais propensos a compra por impulso (RAMYA; ALI, 2016); e que o relacionamento social e o comportamento de compra por impulso são estimulados por meio do 
compartilhamento de imagens por usuários e por mídias patrocinadas em mídias sociais (XIANG et al., 2016). Os achados dos pesquisadores Zhang et al. (2018) demonstraram que valores utilitários e hedônicos aumentam a impulsividade de leitores de comentários on-line e como consequência desencadeiam o comportamento de compra por impulso.

Para compreender a impulsividade do consumidor e outras características inerentes ao seu comportamento, os autores Ramya e Ali (2016) destacam que é necessário entender vários fatores que podem influenciar o comportamento de compra como: a cultura, subcultura, classe social, grupos de interesse, família, amigos, personalidade e fatores psicológicos. Esses fatores atuam em conjunto ou isolados em todo o processo de compra (RAMYA; ALI, 2016). Todos esses fatores associados ao ambiente digital tornam desafiadora a busca dos profissionais de marketing por uma proposição de valor que atinja e atraia seus clientes (RAMYA; ALI, 2016; XIANG et al., 2016). Dificultando, inclusive, a criação de alternativas que promovam mudanças, favoráveis, no comportamento de consumidores alvos para seus negócios (SHAMOUT, 2016).

\section{PROCEDIMENTOS METODOLÓGICOS}

Este artigo possui caráter descritivo com tratamento quantitativo dos dados através da bibliometria como estratégia de pesquisa. A técnica bibliométrica possibilita uma análise do estado da ciência por meio do acesso e análise de artigos que estejam devidamente registrados em bancos de dados, possui grande relevância científica permitindo identificar e analisar tendências e análises de temas relevantes (LAZZAROTI; DALFOVO; HOFFMANN, 2011; SOARES et al., 2016).

A presente pesquisa cuidou em atender leis fundamentais da bibliometria, como: a Lei de Lortka, que propõe analisar quantitativamente a produção por pesquisadores, identificando os autores e quantidade de produções em determinada área, sendo este um importante indicador de produtividade (MACHADO JUNIOR et al., 2016). A Lei de Brandfort, que propõe a análise quantitativa dos periódicos que publicam sobre o tema, com o objetivo de quantificar, descrever e prognosticar o processo de comunicação escrita (MACHADO JUNIOR et al., 2016).

A primeira etapa dessa pesquisa caracterizou-se com a busca sistemática na literatura nacional e internacional dos termos em português: "marketing digital" (e seus variantes: internet marketing, marketing on-line e e-Marketing) e "comportamento de compra" e em inglês: "digital marketing" (e seus variantes: internet marketing, on-line marketing e e-Marketing) e "buying behavior", em cinco bases de dados que indexam publicações cientificas nacionais e internacionais: Ebsco, Periódicos Capes, Scopus, Spell e Web of Science. A seleção destas baseou-se no fato de que tais bases acomodam as principais revistas e journals da área de administração e marketing.

Após a busca inicial foram aplicados os seguintes filtros para lapidação dos dados: acesso livre; texto completo; revisão por pares; escrita nos idiomas português ou inglês; e cuja publicação tenha ocorrido entre os anos de 2000 a 2019, tendo sido o mês de outubro de 2019 o período em que a coleta de dados foi realizada.

As etapas realizadas no processo de seleção dos artigos deste trabalho estão ilustradas na Figura 1. A primeira busca, que compreendeu apenas da utilização dos termos, obteve um total de 3.584 resultados. Após a aplicação dos filtros pré-definidos para essa pesquisa obtiveram-se 2.840 exclusões, resultando em 744 artigos. Na sequência, foram excluídos 181 artigos que estavam repetidos entre as bases. Os 563 artigos restantes foram submetidos à análise de títulos e resumos, nessa etapa excluiu-se 451 artigos que não possuíam ligação direta com o tema proposto, ou seja, apesar de conterem os termos pesquisados estes artigos, em sua maioria, por se tratar de outras áreas de estudo não possuíam aderência ao estudo de comportamento de comportamento de compra. Os 112 artigos restantes foram analisados de forma integral, e, nesta análise, 21 foram excluídos por terem como tema central assuntos diversos da área de marketing, mas não abordavam a relação de influência do marketing digital e o comportamento de compra. Deste modo a amostra final dessa pesquisa foi composta por 91 artigos, como demonstrado na Figura 1. Por inviabilidade, devido à restrição do número de páginas, não será possível apresentar as referências dos 91 artigos que compõe a amostra desse trabalho. 
Figura 1 - Ilustração das etapas do processo de seleção dos trabalhos
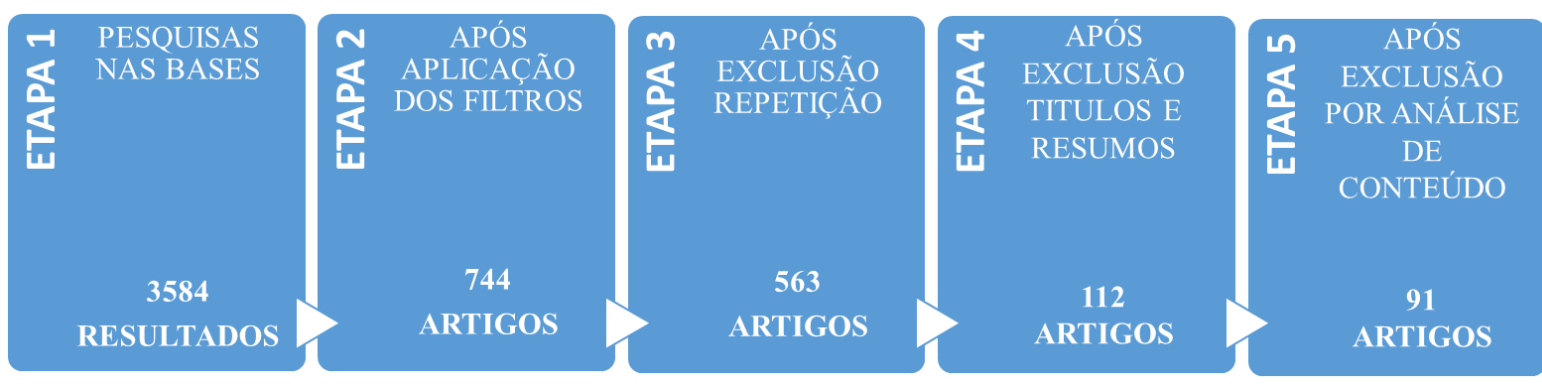

Fonte: Elaboração Própria (2020).

De modo complementar e visando o aprofundamento nos artigos analisados e a apresentação de uma agenda de pesquisa robusta envolvendo o tema estudado, este trabalho também se dedicou à análise qualitativa dos dados por meio da revisão sistemática integrativa. A revisão sistemática integrativa propõe uma apresentação objetiva de um determinado tema, possibilitando uma visão geral evidenciando tendências e lacunas existentes. Esta técnica de pesquisa propõe uma busca exaustiva nas publicações, respeitando critérios de seleção e análise em profundidade dos textos (GALVÃO; SAWADA; TREVISAN, 2004).

A partir da revisão sistemática integrativa foi possível analisar as publicações, agrupando-as por afinidade de tema e separando-as em quatro períodos de cinco anos (de 2000 a 2019). A separação das publicações em quatro períodos permite identificar a evolução dos objetivos e resultados das pesquisas, identifica os direcionamentos e as mudanças das discussões, evidencia o surgimento de temas emergentes e contribui, também, para elaboração de uma agenda de pesquisa mais robusta, cujo propósito é orientar novos pesquisadores.

\section{APRESENTAÇÃO E ANÁLISE DOS RESULTADOS}

Esta seção dedica-se a apresentação e análise de resultados de forma quantitativa e qualitativa.

\subsection{Análise Quantitativa: Bibliometria}

O processo descrito na sessão anterior culminou em uma amostra de 91 artigos que passaram por uma análise de conteúdo, estes artigos envolveram 244 autores, foram conduzidos em 29 diferentes países e tiveram suas publicações distribuídas em 64 periódicos diferentes. A seguir, apresentar-se-á por meio de figuras, gráficos e tabelas, os resultados quantitativos dessa etapa bibliométrica, atendendo às referidas leis da bibliometria.

O Gráfico 1 mostra que foram encontrados artigos entre os anos de 2002 e 2019, destaca ainda, que mais de $60 \%$ dos artigos foram publicados entre os anos de 2016 e 2019, o que demonstra a atualidade do tema e o interesse da academia em explorar tópicos emergentes que envolvem o marketing digital e o comportamento de compra. 
Gráfico 1 - Análise temporal das publicações

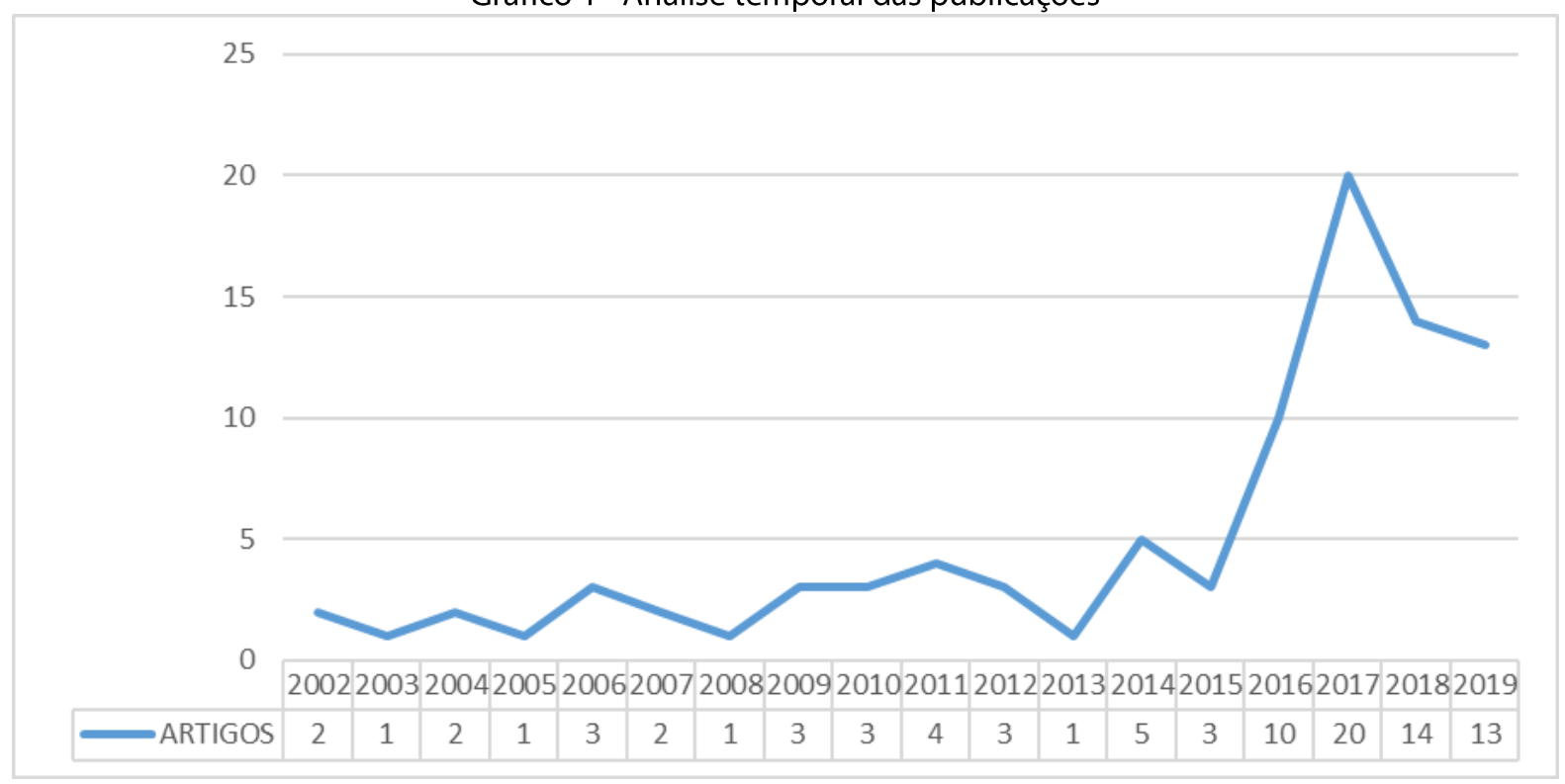

Fonte: Elaboração Própria (2020)

Considerando os países de origem das publicações, observou-se que os estudos conduzidos nos Estados Unidos representam mais de $30 \%$ dos artigos analisados. É notório que os norte-americanos se destacam em várias áreas de pesquisa e, principalmente no tocante às pesquisas de marketing, uma vez que é o berço de tal escola. Ademais, de modo geral, observa-se também, através dos dados dessa pesquisa, uma vasta oportunidade para pesquisadores brasileiros desenvolverem seus estudos e explorar novas teorias ou mesmo validar teorias internacionais no contexto do consumo brasileiro, tendo em vista que o país possui apenas $12 \%$ publicações analisadas.

Em se tratando especificamente dos pesquisadores, a Tabela 1 apresenta os que apresentam maior relevância no que corresponde a quantidade de trabalhos publicados (em autoria ou coautoria), conforme explicita a Lei de Lortka. Desse modo, dentre os 244 autores e coautores dos artigos aqui analisados, são apresentados na Tabela 1 apenas os que participaram em autoria ou coautoria em, pelos menos, dois artigos. Tal tabela demonstra, ainda, o vínculo institucional de cada um deles.

\begin{tabular}{ccc}
\multicolumn{3}{c}{ Tabela 1 - Principais Autores } \\
\hline AUTORES & VíNCULO INSTITUCIONAL & QTD \\
\hline Andrew T. Stephen & University of Oxford & 3 \\
Anindya Ghose & New York University & 2 \\
Edward C. Malthouse & University of Amsterdam & 2 \\
Ewa Maslowska & Northwestern University & 2 \\
Fedorko I. & University of Prešov & 2 \\
Michal Pilik & Tomas Bata University & 2 \\
\hline
\end{tabular}

Fonte: Elaboração Própria (2020)

Os artigos analisados nessa pesquisa foram publicados em 64 diferentes periódicos, destes, 10 são periódicos brasileiros e 54 periódicos internacionais. Os periódicos com o maior número de publicação foram: Journal of Marketing e o Sustainability ambos internacionais e com 6 publicações cada, seguidos do periódico Journal of Theoretical and Applied Electronic Commerce Research, com 4 publicações.

Com a finalidade de identificar os artigos com maior impacto em número de citações, fora conduzida uma pesquisa na base do Google Scholar em 10 de março de 2020. A partir das informações coletadas construiu-se a Tabela 3 apenas com os 5 artigos que apresentaram o maior número de citações. Essa informação permite que pesquisadores interessados no tema tenham acesso a esses trabalhos que demonstram sua relevância e robustez pela utilização como referência para outros pesquisadores. 
Tabela 2 - Artigos mais citados segundo o Google Scholar

\section{ARTIGO}

ZHU, F.; ZHANG, X. Impact of online consumer reviews on sales: The moderating role of 1972 product and consumer characteristics. Journal of marketing, v. 74, n. 2, p. 133-148, 2010. FORMAN, C.; GHOSE, A.; WIESENFELD, B. Examining the relationship between reviews and sales: The role of reviewer identity disclosure in electronic markets. Information systems research, v. 19, n. 3, p. 291-313, 2008.

HAUSER, J.; TELLIS, G. J.; GRIFFIN, A. Research on innovation: A review and agenda for marketing science. Marketing science, v. 25, n. 6, p. 687-/717, 2006.

GHOSE, A.; YANG, S. An empirical analysis of search engine advertising: Sponsored search in electronic markets. Management science, v. 55, n. 10, p. 1605-1622, 2009.

CHEN, Y.; WANG, Q.; XIE, J. Online social interactions: $A$ natural experiment on word of mouth versus observational learning. Journal of marketing research, v. 48, n. 2, p. 238-254, 2011.

Fonte: Elaboração Própria (2020)

\subsection{Análise Qualitativa: Revisão Sistemática Integrativa}

A análise qualitativa do trabalho foi realizada por meio de uma revisão sistemática integrativa, identificando os procedimentos metodológicos das pesquisas, agrupando por afinidade de tema e dividindo as publicações analisadas em conjuntos de cinco anos. O principal objetivo da divisão temporal dos trabalhos analisados é permitir aos leitores identificar a chegada de novos tópicos com os passar dos anos, mudanças de objetivos de determinados temas e a diferenças entre os principais resultados obtidos pelos pesquisadores.

\subsubsection{Análise dos procedimentos metodológicos}

A Tabela 4 apresenta um compilado das informações quanto aos procedimentos metodológicos adotados pelos 91 artigos analisados neste estudo.

Tabela 3 - Procedimentos metodológicos

\begin{tabular}{ccccc}
\hline ESTRATÉGIA DE PESQUISA & \multicolumn{4}{c}{ ABORDAGEM } \\
Estudo de Caso & Teórica & Qualitativa & Quantitativa & Mista \\
Revisão da Literatura & - & - & 1 & - \\
História Oral Temática & 13 & - & - & - \\
Survey & - & - & - & - \\
Levantamento de Dados & - & - & 11 & - \\
Secundários & - & - & 13 & - \\
$\begin{array}{c}\text { Experimento } \\
\text { Quase Experimento }\end{array}$ & - & - & 1 & - \\
Survey/História Oral Temática & - & - & - & 3 \\
Survey/Levantamento de dados & - & & 1 & - \\
secundários & & &
\end{tabular}

Fonte: Elaboração Própria (2020)

A maior parte dos trabalhos analisados adotaram métodos quantitativos, com um destaque para a utilização de surveys como estratégia de coleta de dados. Os experimentos destacaram-se, pois figuraram como estratégia de pesquisa de $14 \%$ dos artigos analisados.

Nota-se que poucos estudos tiveram abordagem qualitativa, chamando atenção para a oportunidade que muitos pesquisadores possuem para conduzir pesquisas qualitativas com o objetivo de aprofundar-se 
mais em dimensões ainda não muito explicadas pela literatura ou mesmo aquelas que sofreram mudanças e transformações em razão do contexto socioeconômico e mudanças culturais.

Vale destacar que pesquisas mistas (qualitativas e quantitativas) também são uma oportunidade para maximizar as análises e potencializar as contribuições em pesquisas de comportamento do consumidor (VASCONCELOS, 2014), nota-se que poucos artigos, dentre os analisados, utilizaram da abordagem mista de pesquisa, representando uma notável oportunidade para os pesquisadores interessados no tema.

\subsubsection{Publicações de 2000 a 2004}

Nesse primeiro período, de 2000 a 2004, observa-se que os trabalhos tinham objetivos exploratórios e buscavam analisar o marketing digital e o comportamento de compra identificando fatores, níveis de conhecimento e estratégias utilizadas por empresas de comércio eletrônico para atrair e reter clientes. $O$ Quadro 1 agrupa os trabalhos por afinidade de temas.

Quadro 1 - Agrupamento por afinidade de tema artigos de 2000 a 2004

\begin{tabular}{|c|c|c|c|}
\hline TEMA PRINCIPAL & QTD & OBJETIVOS & PRINCIPAIS RESULTADOS \\
\hline $\begin{array}{l}\text { COMPORTAMENTO } \\
\text { DE COMPRA ON-LINE }\end{array}$ & 2 & $\begin{array}{c}\text { Entender os fatores de } \\
\text { atração e retenção de } \\
\text { clientes para lojas on-line } \\
\text { e as diferenças no } \\
\text { comportamento de } \\
\text { compra }\end{array}$ & $\begin{array}{l}\text { Os fatores de retenção e atração depende } \\
\text { do objetivo da compra, mas o preço é uma } \\
\text { dimensão base em todos os objetivos } \\
\text { estudados, não existe diferenças } \\
\text { significativas no comportamento de } \\
\text { compra entre homens e mulheres. }\end{array}$ \\
\hline $\begin{array}{l}\text { ESTRATÉGIAS DE } \\
\text { MARKETING DIGITAL }\end{array}$ & 2 & $\begin{array}{l}\text { Fornecer insights } \\
\text { envolvendo as mudanças } \\
\text { trazidas pelo marketing } \\
\text { digital e investigar a } \\
\text { utilização de algumas } \\
\text { dessas estratégias }\end{array}$ & $\begin{array}{c}\text { A internet trouxe várias mudanças dentre } \\
\text { elas impulsionou a estratégia competitiva } \\
\text { das empresas. O uso de estratégias de } \\
\text { marketing digital como banners } \\
\text { patrocinados em comunidades on-line } \\
\text { aumenta a percepção de qualidade e } \\
\text { intenção de compra de consumidores } \\
\text { conectados. }\end{array}$ \\
\hline $\begin{array}{c}\text { SITES DE } \\
\text { RECLAMAÇÃO }\end{array}$ & 1 & $\begin{array}{l}\text { Entender o nível de } \\
\text { conhecimento de sites de } \\
\text { reclamação e o quanto } \\
\text { impacta em seu } \\
\text { comportamento }\end{array}$ & $\begin{array}{c}\text { A maior parte dos participantes conhecem } \\
\text { e visitam esses sites e assumem que o } \\
\text { conteúdo deles influencia seu } \\
\text { comportamento }\end{array}$ \\
\hline
\end{tabular}

Fonte: Elaboração própria (2020)

Nesse período destaca-se o estudo das seguintes dimensões: preço, satisfação, manutenção de clientes, atração de clientes, busca patrocinada, diferenças culturais e atitude. Também foi explorado as diferenças de comportamento ente homens e mulheres. As pesquisas também focaram evidenciar as mudanças comportamentais provocadas pela internet tanto na perspectiva dos consumidores quanto na perspectiva das empresas.

\subsubsection{Publicações de 2005 a 2009}

O período de 2005 a 2009 fora marcado pela discussão de vários temas ligados ao aumento da interação do consumidor na internet, gerando conteúdo e acessando as plataformas de compra on-line, destaca-se a preocupação dos pesquisadores em resgatar toda a literatura do marketing tradicional e aprofundar-se em algumas características do comportamento do consumidor no ambiente digital. O Quadro 2 apresenta os artigos agrupados por afinidade. 
Quadro 2 - Agrupamento por afinidade de tema artigos de 2005 a 2009

\begin{tabular}{|c|c|c|c|}
\hline TEMA PRINCIPAL & QTD & OBJETIVOS & PRINCIPAIS RESULTADOS \\
\hline $\begin{array}{l}\text { COMPORTAMENTO } \\
\text { DE COMPRA ON- } \\
\text { LINE }\end{array}$ & 4 & $\begin{array}{l}\text { Analisar os perfis dos } \\
\text { consumidores que compram } \\
\text { através da internet e mensurar } \\
\text { os atributos que influenciam } \\
\text { os consumidores quanto a } \\
\text { satisfação com a tecnologia } \\
\text { durante o comportamento de } \\
\text { compra }\end{array}$ & $\begin{array}{c}\text { Os mais jovens são mais aderentes a realizar } \\
\text { compras on-line e são mais influenciados } \\
\text { para tal devido a alta conectividade, as mães } \\
\text { brasileiras tendem a usar a internet para } \\
\text { pesquisar acerca de temas de saúde e a } \\
\text { praticidade, intuitividade são atributos } \\
\text { importantes no uso de tecnologias para } \\
\text { compras. }\end{array}$ \\
\hline $\begin{array}{l}\text { A INFLUÊNCIA DOS } \\
\text { REVIEWS } \\
\text { (COMENTÁRIOS) } \\
\text { ON-LINE }\end{array}$ & 2 & $\begin{array}{c}\text { Examinar a influência dos } \\
\text { comentários on-line no } \\
\text { comportamento de compra e a } \\
\text { influência da identidade do } \\
\text { revisor }\end{array}$ & $\begin{array}{l}\text { Os comentários on-line são ativamente } \\
\text { consultados pelos usuários da internet e os } \\
\text { sites que permitem a identificação do revisor } \\
\text { são mais consultados e recebem maior } \\
\text { credibilidade dos consumidores }\end{array}$ \\
\hline $\begin{array}{l}\text { MARKETING BOCA } \\
\text { A BOCA ON-LINE } \\
\text { (WOM) }\end{array}$ & 1 & $\begin{array}{c}\text { Criar uma métrica de } \\
\text { densidade de indicações e } \\
\text { avaliações de consumidores na } \\
\text { internet }\end{array}$ & $\begin{array}{c}\text { As interações de indivíduos na internet } \\
\text { aumentam a predisposição dos } \\
\text { consumidores fazerem também marketing } \\
\text { boca a boca off-line. Os autores criaram uma } \\
\text { métrica capaz de medir a densidade das } \\
\text { interações. }\end{array}$ \\
\hline $\begin{array}{l}\text { MIGRAÇÃO DO OFF } \\
\text { LINE PARA O ON- } \\
\text { LINE }\end{array}$ & 2 & $\begin{array}{l}\text { Identificar variáveis que } \\
\text { influencia a escolha do } \\
\text { consumidor por comprar via } \\
\text { internet }\end{array}$ & $\begin{array}{l}\text { Os baixos preços dos produtos vendidos via } \\
\text { internet e a conveniência são os principais } \\
\text { fatores de influência. }\end{array}$ \\
\hline $\begin{array}{c}\text { BUSCA } \\
\text { PATROCINADA }\end{array}$ & 1 & $\begin{array}{l}\text { Entender os fatores e métricas } \\
\text { utilizadas para mensurar os } \\
\text { resultados de buscas } \\
\text { patrocinadas }\end{array}$ & $\begin{array}{c}\text { Identificou-se que é possível monetizar os } \\
\text { cliques oriundos de uma estratégia de } \\
\text { marketing digital. Quanto mais na parte } \\
\text { superior da tela maiores são as taxas de } \\
\text { conversão e menor o valor investido por } \\
\text { clique }\end{array}$ \\
\hline
\end{tabular}

Fonte: Elaboração própria (2020)

Variáveis como preço, densidade de interações, engajamento, conveniência, confiança, intenção de compra e utilidade percebida permearam as discussões nesse período. Observa-se a preocupação dos pesquisadores em desenvolver métricas capazes de avaliar a relação entre diferentes estratégias de marketing digital e o comportamento de compra dos consumidores.

\subsubsection{Publicações de 2010 a 2014}

Nesse período é notório o aumento do número de trabalhos publicados e a expansão de temas principais e objetos de pesquisa, destaca-se o aprofundamento dos temas: marketing boca a boca, análise da influência do marketing digital no comportamento de compra e a análise do fenômeno de compra de grupo on-line que ganhou mais adeptos ao decorrer dos anos com o auxílio das mídias sociais. O Quadro 3 apresenta o agrupamento por afinidade dos artigos publicados nesse período. 
Quadro 3 - Agrupamento por afinidade de tema artigos de 2010 a 2014

\begin{tabular}{|c|c|c|c|}
\hline TEMA PRINCIPAL & QTD & OBJETIVOS & PRINCIPAIS RESULTADOS \\
\hline $\begin{array}{l}\text { COMPORTAMENTO } \\
\text { DE COMPRA ON- } \\
\text { LINE }\end{array}$ & 7 & $\begin{array}{l}\text { Analisar a percepção de } \\
\text { segurança dos compradores } \\
\text { on-line. Identificar a } \\
\text { influência das mídias sociais } \\
\text { no comportamento de } \\
\text { compra e investigar a } \\
\text { importância do } \\
\text { reconhecimento de marca } \\
\text { no comércio eletrônico }\end{array}$ & $\begin{array}{l}\text { Os consumidores tendem a visitar mais } \\
\text { vezes sites bem gerenciados, com interface } \\
\text { segura e atrativa. As redes sociais influência } \\
\text { no processo de compra on-line e estimula } \\
\text { experiências com novas modalidades de } \\
\text { compra. O reconhecimento de marca é } \\
\text { fundamental para o consumidor sentir-se } \\
\text { seguro no processo de compra on-line }\end{array}$ \\
\hline $\begin{array}{l}\text { A INFLUÊNCIA DOS } \\
\text { REVIEWS } \\
\text { (COMENTÁRIOS) ON- } \\
\text { LINE }\end{array}$ & 1 & $\begin{array}{l}\text { Examinar a influência dos } \\
\text { comentários on-line no } \\
\text { comportamento de compra } \\
\text { do consumidor }\end{array}$ & $\begin{array}{c}\text { O conhecimento dos produtos e suas } \\
\text { características influenciam diretamente nos } \\
\text { comentários on-line acerca dos produtos ou } \\
\text { marca, as empresas precisam disseminar o } \\
\text { conhecimento das características de seus } \\
\text { produtos para ter maior proveito dos } \\
\text { comentários on-line. }\end{array}$ \\
\hline $\begin{array}{c}\text { MARKETING BOCA A } \\
\text { BOCA (WOM) }\end{array}$ & 2 & $\begin{array}{l}\text { Identificar o impacto e } \\
\text { influência do marketing } \\
\text { boca a boca digital e } \\
\text { investigar o engajamento e } \\
\text { satisfação dos nativos } \\
\text { digitais (jovens muito } \\
\text { conectados) }\end{array}$ & $\begin{array}{l}\text { O marketing boca a boca negativo possui } \\
\text { impacto e maiores efeitos do que o } \\
\text { positivo. Os nativos digitais (jovens que } \\
\text { nasceram na geração da internet) são ativos } \\
\text { influenciadores e são influenciados pelo } \\
\text { marketing boca a boca }\end{array}$ \\
\hline $\begin{array}{l}\text { COMPRAS DE } \\
\text { GRUPO (COMPRAS } \\
\text { COLETIVAS) ON-LINE }\end{array}$ & 2 & $\begin{array}{l}\text { Identificar e descrever o } \\
\text { fenômeno de compras } \\
\text { coletivas on-line e os fatores } \\
\text { que melhoram a intenção de } \\
\text { compra dessa modalidade }\end{array}$ & $\begin{array}{l}\text { Três fatores: a experiência de compra de } \\
\text { grupo on-line, a qualidade do site e a } \\
\text { qualidade do varejista on-line, possuem } \\
\text { efeito positivo significativo na intenção de } \\
\text { compra do grupo on-line, tecnologia de } \\
\text { geolocalização podem aumentar as vendas } \\
\text { nessa categoria. }\end{array}$ \\
\hline $\begin{array}{c}\text { BUSCA } \\
\text { PATROCINADA }\end{array}$ & 1 & $\begin{array}{c}\text { Examinar a concorrência } \\
\text { entre empresas que utilizam } \\
\text { o recurso de busca } \\
\text { patrocinada }\end{array}$ & $\begin{array}{l}\text { Muitos consumidores são atingidos por essa } \\
\text { estratégia, cada vez mais comum a } \\
\text { utilização de sites de buscas, as empresas } \\
\text { que fazem investimentos por posições na } \\
\text { parte superior da busca possuem maior } \\
\text { retorno do investimento }\end{array}$ \\
\hline $\begin{array}{l}\text { INFLUÊNCIA DAS } \\
\text { MÍDIAS SOCIAIS NO } \\
\text { COMPORTAMENTO } \\
\text { DE COMPRA }\end{array}$ & 2 & $\begin{array}{l}\text { Examinar a utilização das } \\
\text { redes sociais para interagir } \\
\text { com consumidores e } \\
\text { aumentar a percepção de } \\
\text { qualidade }\end{array}$ & $\begin{array}{c}\text { As mídias sociais tornaram-se uma } \\
\text { ferramenta efetiva para interação com } \\
\text { consumidores, aumentar o conhecimento } \\
\text { de marca e divulgação de conteúdo que } \\
\text { aumentem a percepção de qualidade dos } \\
\text { produtos }\end{array}$ \\
\hline $\begin{array}{l}\text { MARKETING VIRAL } \\
\text { ON-LINE }\end{array}$ & 1 & $\begin{array}{c}\text { Conceituar "marketing viral" } \\
\text { nas redes sociais e } \\
\text { demonstrar aspectos prático } \\
\text { e teóricos }\end{array}$ & $\begin{array}{c}\text { O marketing viral consiste em uma } \\
\text { estratégia eficaz, porém não garantem as } \\
\text { consequências desejadas e deve ser usado } \\
\text { com muita cautela }\end{array}$ \\
\hline
\end{tabular}

Fonte: Elaboração própria (2020)

Nesse período as discussões giraram em torno de variáveis como: segurança, qualidade, design e acessibilidade. A descrição, comparação e investigação de comportamento de compra de diferentes perfis, sexos e gerações foram realizadas por alguns pesquisadores com intuito de demonstrar e comprovar as possíveis contribuições em torno do marketing digital. 
O período de 2015 a 2019 destaca-se por ser o detentor do maior volume de publicações. Tema como o "comportamento de compra on-line"e a "influência das mídias sociais no comportamento de compra", foram largamente explorados.

Temas emergentes em marketing aparecem explorados sob a ótica do comportamento de compra, como: "IOT", "economia compartilhada", "marketing sensorial digital" e "marketing digital e sustentabilidade". Estes temas ainda estão incipientes e, dessa forma, carecem de maiores investigações e compreensões por pesquisas nas áreas de marketing.

Quadro 4 - Agrupamento por afinidade de tema artigos de 2015 a 2019

\begin{tabular}{|c|c|c|c|}
\hline TEMA PRINCIPAL & QTD & OBJETIVOS & PRINCIPAIS RESULTADOS \\
\hline $\begin{array}{l}\text { COMPORTAMENTO } \\
\text { DE COMPRA ON- } \\
\text { LINE }\end{array}$ & 19 & $\begin{array}{l}\text { Identificar, descrever e } \\
\text { analisar dimensões, } \\
\text { atributos, características, } \\
\text { categorias e variáveis } \\
\text { envolvendo o } \\
\text { comportamento de } \\
\text { compra on-line. } \\
\text { Segmentar usuários, } \\
\text { identificar fatores } \\
\text { influenciam o } \\
\text { comportamento de } \\
\text { compra on-line }\end{array}$ & $\begin{array}{l}\text { Sites e redes sociais são fontes primárias de } \\
\text { pesquisa on-line. Campanhas focadas em prazer e } \\
\text { interação social aumentam a intenção de compra } \\
\text { dos consumidores. Reputação, qualidade, } \\
\text { conveniência, preço e possibilidade de comparar } \\
\text { preços figuram entre os principais fatores de } \\
\text { influência interna do comportamento de compra } \\
\text { on-line. Destaca-se que quanto maior a idade } \\
\text { maior enfoque é dado para o fator conveniência. } \\
\text { Entre os fatores externos encontram-se: cultura, } \\
\text { família e amigos, a maioria influencia através das } \\
\text { mídias sociais. }\end{array}$ \\
\hline $\begin{array}{l}\text { A INFLUÊNCIA DOS } \\
\text { REVIEWS } \\
\text { (COMENTÁRIOS) } \\
\text { ON-LINE }\end{array}$ & 4 & $\begin{array}{l}\text { Identificar e Analisar os } \\
\text { fatores que envolvam os } \\
\text { comentários on-line seu } \\
\text { impacto em vendas e } \\
\text { influência no } \\
\text { comportamento de } \\
\text { compra dos } \\
\text { consumidores } \\
\end{array}$ & $\begin{array}{l}\text { Os comentários em sites e redes sociais } \\
\text { influenciam muito o comportamento de compra, } \\
\text { porém alguns achados sugerem que nem sempre } \\
\text { as vendas crescem em conformidade com o } \\
\text { aumento quantidade de comentários on-line. Os } \\
\text { comentários via mobile (quando assim } \\
\text { identificados) ganham maior credibilidade do que } \\
\text { os realizados por outros dispositivos }\end{array}$ \\
\hline $\begin{array}{c}\text { MARKETING BOCA } \\
\text { A BOCA (WOM) }\end{array}$ & 3 & $\begin{array}{l}\text { Analisar o efeito } \\
\text { investigar o impacto do } \\
\text { design dos sites na } \\
\text { intenção do marketing } \\
\text { boca a boca on-line }\end{array}$ & $\begin{array}{l}\text { Trata-se de um fenômeno que apesar de não } \\
\text { poder ser controlado pelas empresas ele pode ser } \\
\text { devidamente fomentado, porém quando negativo } \\
\text { traz problemas profundos. O design dos sites } \\
\text { influencia muito na intenção recomendá-lo. }\end{array}$ \\
\hline $\begin{array}{l}\text { COMPRAS DE } \\
\text { GRUPO (COMPRAS } \\
\text { COLETIVAS) ON- } \\
\text { LINE }\end{array}$ & 1 & $\begin{array}{c}\text { Investigar os efeitos } \\
\text { moderadores e } \\
\text { mediadores da } \\
\text { personalidade influência } \\
\text { social em relação à } \\
\text { compra de grupos on- } \\
\text { line }\end{array}$ & $\begin{array}{l}\text { Os níveis de cooperação dos indivíduos, têm } \\
\text { efeitos diferentes sobre } \\
\text { valores coletivísticos por meio de intenções em } \\
\text { relação à compra de grupo, não fora encontrado } \\
\text { efeitos diretos de valores culturais na compra de } \\
\text { grupo on-line }\end{array}$ \\
\hline $\begin{array}{l}\text { CONTEÚDO } \\
\text { GERADO PELO } \\
\text { USÚARIO } \\
\text { (UGC) }\end{array}$ & 2 & $\begin{array}{l}\text { Investigar o uso } \\
\text { hedônico e utilitário do } \\
\text { conteúdo gerado pelo } \\
\text { usuário e analisar o } \\
\text { impacto no } \\
\text { comportamento de } \\
\text { compra e valor de marca }\end{array}$ & $\begin{array}{l}\text { Os consumidores utilizam o UGC porque é } \\
\text { agradável, principalmente no aspecto utilitário } \\
\text { tornando-se essa fonte mais confiável do que as da } \\
\text { própria empresa. A análise do UGC permite } \\
\text { mensuração do valor da marca e possíveis } \\
\text { impactos futuros na reputação }\end{array}$ \\
\hline $\begin{array}{l}\text { INFLUÊNCIA DAS } \\
\text { MÍDIAS SOCIAIS NO } \\
\text { COMPORTAMENTO } \\
\text { DE COMPRA }\end{array}$ & 20 & $\begin{array}{l}\text { Analisar a relação de } \\
\text { influência das mídias } \\
\text { sociais e o } \\
\text { comportamento de }\end{array}$ & $\begin{array}{l}\text { A relação de confiança construída por meio das } \\
\text { mídias sociais figurou como determinante do } \\
\text { comportamento de compra, o grau de } \\
\text { interatividade com a marca nas redes sociais é }\end{array}$ \\
\hline
\end{tabular}




\begin{tabular}{|c|c|c|c|}
\hline & & $\begin{array}{l}\text { compra dos } \\
\text { consumidores e a } \\
\text { relação entre compras } \\
\text { on-line e interatividade } \\
\text { com a marca nas mídias } \\
\text { sociais. } \\
\end{array}$ & $\begin{array}{l}\text { fator impulsionador das intenções de compra. As } \\
\text { redes sociais influenciam em larga escala o } \\
\text { comportamento de compra dos consumidores e } \\
\text { possuem efeitos no fomento de consumo }\end{array}$ \\
\hline $\begin{array}{l}\text { MARKETING } \\
\text { DIGITAL E A } \\
\text { ECONÔMIA } \\
\text { COMPARTILHADA }\end{array}$ & 1 & $\begin{array}{l}\text { Explorar de que modo o } \\
\text { marketing digital } \\
\text { podem contribuir com } \\
\text { organizações na } \\
\text { economia } \\
\text { compartilhada } \\
\end{array}$ & $\begin{array}{l}\text { Recursos incorporados de confiança, utilidade e } \\
\text { experiência do usuário, os aplicativos móveis estão } \\
\text { constantemente disponíveis para } \\
\text { usuários de smartphones e contribuem } \\
\text { significativamente com o desenvolvimento de } \\
\text { organizações focadas em economia compartilhada }\end{array}$ \\
\hline $\begin{array}{l}\text { INFLUENCIADORES } \\
\text { DIGITAIS }\end{array}$ & 2 & $\begin{array}{l}\text { Identificar como os } \\
\text { influenciadores digitais } \\
\text { através de suas mídias } \\
\text { influenciam o } \\
\text { comportamento de } \\
\text { compra de seus } \\
\text { seguidores }\end{array}$ & $\begin{array}{l}\text { Compartilhando suas experiências diárias e } \\
\text { fazendo demonstração de diversos produtos e } \\
\text { marcas são atividades que demonstraram grande } \\
\text { influência no comportamento de compra dos } \\
\text { seguidores, por meio da confiança e admiração. }\end{array}$ \\
\hline $\begin{array}{l}\text { INTEGRAÇÃO ON- } \\
\text { LINE E OFF-LINE }\end{array}$ & 1 & $\begin{array}{l}\text { Identificar como os } \\
\text { consumidores adotam a } \\
\text { integração do on-line e } \\
\text { off-line no momento da } \\
\text { compra }\end{array}$ & $\begin{array}{l}\text { Principais motivos dos consumidores realizar } \\
\text { compras nos canais físicos estão a qualidade de } \\
\text { serviço agregado e o menor risco de erros. Porém } \\
\text { mesmo nesses casos os consumidores realizam } \\
\text { pesquisas on-line e nas redes sociais para subsidiar } \\
\text { a decisão e comparação de preços }\end{array}$ \\
\hline $\begin{array}{c}\text { IOT (INTERNET DAS } \\
\text { COISAS) }\end{array}$ & 1 & $\begin{array}{c}\text { Revisar o uso de internet } \\
\text { das coisas em Marketing } \\
\text { Digital e os principais } \\
\text { problemas associados }\end{array}$ & $\begin{array}{c}\text { O IOT tem sido utilizados em estratégias e } \\
\text { marketing digital, porém as empresas devem } \\
\text { garantir que os dados dos consumidores no uso de } \\
\text { IOT estejam seguros }\end{array}$ \\
\hline $\begin{array}{c}\text { MARKETING } \\
\text { SENSORIAL DIGITAL }\end{array}$ & 1 & $\begin{array}{c}\text { Ajudar o leitor a } \\
\text { entender melhor o } \\
\text { marketing sensorial no } \\
\text { contexto digital } \\
\end{array}$ & $\begin{array}{l}\text { Em um futuro próximo novas tecnologias mudarão } \\
\text { totalmente o comportamento do consumidor com } \\
\text { integrações sensoriais que irá revolucionar o } \\
\text { comportamento de compra }\end{array}$ \\
\hline PROTESTO ON-LINE & 1 & $\begin{array}{l}\text { Investigar os efeitos que } \\
\text { protestos on-line na } \\
\text { avaliação dos acionistas } \\
\text { e consumidores }\end{array}$ & $\begin{array}{c}\text { As empresas podem esperar sofrer dificuldades } \\
\text { financeiras, danos à reputação e às vendas quando } \\
\text { um protesto on-line ou } \\
\text { campanha mobiliza os consumidores com sucesso. } \\
\text { Os danos são difíceis de se reparar. }\end{array}$ \\
\hline $\begin{array}{l}\text { SATISFAÇÃO DO } \\
\text { CONSUMIDOR NA } \\
\text { COMPRA ON-LINE }\end{array}$ & 1 & $\begin{array}{l}\text { Identificar os fatores } \\
\text { determinantes para a } \\
\text { satisfação do } \\
\text { consumidor em } \\
\text { compras on-line }\end{array}$ & $\begin{array}{c}\text { A satisfação dos consumidores nas compras on- } \\
\text { line depende diretamente dos seguintes fatores: } \\
\text { segurança, disponibilidade de informações, envio, } \\
\text { qualidade, preço e tempo. }\end{array}$ \\
\hline $\begin{array}{c}\text { SUSTENTABILIDADE } \\
\text { NO MARKETING } \\
\text { DIGITAL }\end{array}$ & 1 & $\begin{array}{l}\text { Examinar a literatura e } \\
\text { avaliar as pesquisas } \\
\text { sobre marketing digital } \\
\text { e sustentabilidade }\end{array}$ & $\begin{array}{c}\text { Os principais desafios do marketing digital e } \\
\text { sustentabilidade são: orientação ao cliente e } \\
\text { proposição de valor; comportamento digital do } \\
\text { consumidor; marketing verde digital; vantagem } \\
\text { competitiva e cadeia de suprimentos; }\end{array}$ \\
\hline $\begin{array}{l}\text { USABILIDADE DOS } \\
\text { SITES }\end{array}$ & 1 & $\begin{array}{l}\text { Examinar a atitude em } \\
\text { relação aos sites por sua } \\
\text { usabilidade, risco } \\
\text { percebido e utilidade } \\
\text { percebida }\end{array}$ & $\begin{array}{l}\text { A usabilidade e a utilidade percebidas exercem } \\
\text { uma influência positiva na atitude em relação ao } \\
\text { site, enquanto o efeito do risco percebido é } \\
\text { negativo, para os negócios de turismo }\end{array}$ \\
\hline
\end{tabular}

Fonte: Elaboração própria (2020) 
Destaca-se, nesse período, a posição de destaque que mídias sociais tiveram nos trabalhos analisados, além dos artigos que as tinham como foco, as mídias sociais foram discutidas e apontadas na maioria dos estudos, mesmo onde elas não eram o objeto principal.

A discussão de variáveis e dimensões como segurança, privacidade dos dados, credibilidade, reputação, qualidade e utilidade percebida são combinadas por vários pesquisadores com intuito de esclarecer a influência das estratégias de marketing digital e comportamento de compra do consumidor e são apresentadas como vitais para os negócios. Esse período fora marcado pelo aprofundamento de muitas discussões envolvendo variáveis como: conveniência, possibilidade de comparação de preços, utilização em dispositivo mobile, design de sites, confiança, admiração, disponibilidade de informações e economia do tempo. Combinadas ou individualizadas, essas variáveis, demonstraram influenciar o comportamento de compra do consumidor, no âmbito do marketing digital.

\subsection{Agenda de Pesquisa}

O Quadro 5 traz uma agenda de pesquisa, com proposições de objetivos para orientar pesquisadores interessados em aprofundar seus estudos nos temas que envolvem o marketing digital e o comportamento de compra do consumidor. Para a construção dessa agenda foram considerados os gaps teóricos e as lacunas existentes na literatura analisada, através de uma revisão sistemática de todos os artigos selecionados.

Quadro 5 - Agenda de Pesquisa

\begin{tabular}{|c|c|c|}
\hline TEMA & REFERÊNCIAS & AGENDA DE PESQUISA \\
\hline $\begin{array}{l}\text { INFLUÊNCIA DAS } \\
\text { MÍDIAS SOCIAIS NO } \\
\text { COMPORTAMENTO } \\
\text { DE COMPRA }\end{array}$ & $\begin{array}{l}\text { Kumar et al. } \\
\text { (2016); } \\
\text { Lamberton e } \\
\text { Stephen } \\
\text { (2016); } \\
\text { Kizgin, et. al. } \\
\text { (2018). }\end{array}$ & $\begin{array}{l}\text { 1. Pesquisar como a privacidade tem sido respeitada } \\
\text { pelas organizações que usam as mídias sociais para } \\
\text { relacionar-se com seus consumidores; } \\
\text { 2. Compreender as mudanças na tomada de decisão } \\
\text { dos consumidores devido a experiências digitais; } \\
\text { 3. Identificar os fatores e métricas que caracteriza uma } \\
\text { iniciativa digital como bem-sucedida; } \\
\text { 4. Desenvolver estudos longitudinais para } \\
\text { compreender como a interação on-line com marcas } \\
\text { influencia no comportamento de compra. }\end{array}$ \\
\hline $\begin{array}{c}\text { COMPORTAMENTO } \\
\text { DE COMPRA ON- } \\
\text { LINE }\end{array}$ & $\begin{array}{l}\text { Reibstein (2002); } \\
\text { Stafford, Tura e } \\
\text { Raisinghani } \\
\text { (2004); } \\
\text { Yen } \\
\text { (2005); } \\
\text { Dai et al. } \\
\text { (2018). }\end{array}$ & $\begin{array}{l}\text { 1. Identificar e comparar idades e classe social de } \\
\text { consumidores do comércio eletrônico alcançados } \\
\text { pelas redes sociais; } \\
\text { 2. Analisar tendências relacionadas às seguintes } \\
\text { áreas: compra sustentável e ética, compras na } \\
\text { economia digital, gerenciamento de riscos da } \\
\text { cadeia de suprimentos; } \\
\text { 3. Considerar e, principalmente, empregar } \\
\text { separadamente a análise dos riscos inerentes e a } \\
\text { análise dos riscos manipulados em estudos do } \\
\text { comportamento do consumidor nas compras on- } \\
\text { line. }\end{array}$ \\
\hline $\begin{array}{l}\text { MARKETING } \\
\text { DIGITAL E A } \\
\text { ECONÔMIA } \\
\text { COMPARTILHADA }\end{array}$ & Key (2017). & $\begin{array}{l}\text { 1. Desenvolver estudos transculturais para entender } \\
\text { as relações internas e externas da adoção de } \\
\text { economia compartilhada; } \\
\text { 2. Explorar o impacto econômico familiar do uso de } \\
\text { tecnologias de economia compartilhada }\end{array}$ \\
\hline $\begin{array}{l}\text { INFLUENCIADORES } \\
\text { DIGITAIS }\end{array}$ & $\begin{array}{c}\text { Hughes et al. } \\
\text { (2019); } \\
\text { Schinaider e Barbosa } \\
\text { (2019). }\end{array}$ & $\begin{array}{l}\text { 1. Pesquisar o retorno de investimentos em } \\
\text { influencers digitais; } \\
\text { 2. Analisar a percepção dos seguidores quanto a } \\
\text { publicidades pagas através de influencers; }\end{array}$ \\
\hline
\end{tabular}




\begin{tabular}{|c|c|c|}
\hline & & $\begin{array}{l}\text { 3. Analisar os fatores determinantes e mediadores da } \\
\text { relação influenciadores e influenciados }\end{array}$ \\
\hline $\begin{array}{l}\text { INTEGRAÇÃO ON- } \\
\text { LINE E OFF-LINE }\end{array}$ & Chiang et al. (2018). & $\begin{array}{l}\text { 1. Investigar a integração on-line e off-line nos } \\
\text { seguimentos de eletrônicos, passagens aéreas e } \\
\text { pacotes de viagem; }\end{array}$ \\
\hline $\begin{array}{l}\text { IOT (INTERNET DAS } \\
\text { COISAS) }\end{array}$ & $\begin{array}{l}\text { Abashidze e } \\
\text { Dąbrowski (2016). }\end{array}$ & $\begin{array}{l}\text { 1. Analisar e identificar as soluções de IOT em } \\
\text { marketing e o seu perfil de segurança das } \\
\text { informações do consumidor; } \\
\text { 2. Explorar como ferramentas de IOT dedicadas a } \\
\text { geolocalização impactam no comportamento de } \\
\text { compra dos consumidores; }\end{array}$ \\
\hline $\begin{array}{l}\text { MARKETING } \\
\text { SENSORIAL } \\
\text { DIGITAL }\end{array}$ & $\begin{array}{l}\text { Petit, Velasco e } \\
\text { Spence } \\
\text { (2019). }\end{array}$ & $\begin{array}{l}\text { 1. Antecipar e analisar como as novas tecnologias } \\
\text { impactará as atitudes e comportamentos do } \\
\text { mercado através da Sensorialização de ambientes } \\
\text { digitais; }\end{array}$ \\
\hline $\begin{array}{c}\text { A INFLUÊNCIA DOS } \\
\text { REVIEWS } \\
\text { (COMENTÁRIOS } \\
\text { ON-LINE) }\end{array}$ & $\begin{array}{c}\text { Zhu e Zhang } \\
\text { (2010); } \\
\text { Kim, Maslowska e } \\
\text { Malthouse } \\
\text { (2018); } \\
\text { Grewal e Stephen } \\
\text { (2019). }\end{array}$ & $\begin{array}{l}\text { 1. analisar teórica e empiricamente a estratégia ideal } \\
\text { das empresas na alocação de marketing recursos } \\
\text { para canais on-line e off-line, orientadas pelos } \\
\text { comentários on-line; } \\
\text { 2. Comparar a influência de comentários on-line entre } \\
\text { vários produtos } \\
\text { 3. Examinar as maneiras pelas quais os comentários } \\
\text { on-line estão afetando psicologicamente os } \\
\text { consumidores e comportamento de compra on- } \\
\text { line; }\end{array}$ \\
\hline $\begin{array}{l}\text { MARKETING BOCA } \\
\text { A BOCA (WOM) }\end{array}$ & $\begin{array}{l}\text { Chen, Wang, e Xie } \\
\qquad(2011) ; \\
\text { Williams et al. (2012); } \\
\text { Herrera, León e } \\
\text { Vargas-Ortiz (2018); } \\
\text { Phan e Pilík (2018). }\end{array}$ & $\begin{array}{l}\text { 1. Realizar estudos transculturais para comparar a } \\
\text { influência cultural na aceitação e na propagação de } \\
\text { marketing boca a boca; } \\
\text { 2. Comparar diferentes categorias de produtos para } \\
\text { evidenciar quais são mais impactadas pelo } \\
\text { marketing boca a boca; } \\
\text { 3. Estudar diferentes eventos de marketing que } \\
\text { resultou em marketing boca a boca negativo a fim } \\
\text { de evidenciar características, dimensões, fatores } \\
\text { envolvidos e similaridades de contextos; }\end{array}$ \\
\hline $\begin{array}{c}\text { MARKETING } \\
\text { DIGITAL E } \\
\text { SUSTENTABILIDAD } \\
\text { E }\end{array}$ & $\begin{array}{l}\text { Diez-Martin e } \\
\text { Blanco-Gonzalez } \\
\text { (2019). }\end{array}$ & $\begin{array}{l}\text { 1. Desenvolver pesquisas que evidencie o perfil de } \\
\text { clientes de empresas/ produtos sustentáveis na } \\
\text { internet; } \\
\text { 2. Identificar quais são os gatilhos que influenciam no } \\
\text { comportamento de compra de clientes, orientados } \\
\text { para produtos sustentáveis } \\
\text { 3. Identificar ferramentas ecológicas de marketing e } \\
\text { como e em quais contextos elas influenciam no } \\
\text { comportamento de seus consumidores }\end{array}$ \\
\hline
\end{tabular}

Fonte: Elaboração Própria (2020).

A análise do estado da arte, proposta por essa pesquisa, demonstrou que a literatura nacional ainda é muito incipiente e há muitas oportunidades para exploração científica. Nesse sentido, a agenda de pesquisa proposta no Quadro 5 visa orientar os pesquisadores para um aprofundamento das discussões em temas que envolvem o marketing digital e comportamento de compra dos consumidores. Observa-se que os estudos analisados não exploraram a segurança dos dados, sob a percepção do consumidor, nas interações via mídias sociais, na compra on-line e na utilização de IOT e suas ferramentas de geolocalização, por exemplo.

Estudos longitudinais, sob a perspectiva empresarial, analisando o retorno financeiro, no curto, médio e longo prazo, da utilização de estratégias de marketing digital, não foram encontrados, assim como estudos longitudinais capazes de evidenciar se a interação em mídias sociais ou plataformas digitais, com marcas, são capazes de influenciar o comportamento de compra de seus usuários. 
Estudos transculturais possuem um grande potencial para contribuições cientificas, pois são capaz de analisar, descrever e até comparar o comportamento de determinado fenômeno em diferentes culturas, sugere-se estudos transculturais que permitam evidenciar características e gatilhos na utilização do marketing boca a boca digital, opção por modalidade de compra em grupo, opções por empresas com iniciativas sustentáveis e envolvendo a compra por impulso.

Outro fenômeno que merece atenção das futuras pesquisas são os influenciadores digitais, geradores de conteúdos em redes sociais, tal fenômeno merece estudos mais aprofundados como por exemplo, evidenciar fatores mediadores e moderadores na relação de influência entre seus seguidores e entender a percepção dos mesmos sobre publicações patrocinadas e indicações de produtos recebidos gratuitamente impacta na credibilidade e no comportamento de compra dos seguidores.

\section{CONSIDERAÇÕES FINAIS}

O avanço tecnológico, as plataformas digitais e outras ferramentas de interação digital transformaram - comportamento de consumo das pessoas e como consequência, a forma como as empresas fazem marketing. A análise bibliométrica desse estudo revelou a atualidade da temática envolvendo o marketing digital e o comportamento de compra dos consumidores. Demonstrou também, a incipiência da literatura brasileira acerca do tema.

O agrupamento das publicações por períodos permitiu identificar as evoluções de objetivos de pesquisas e os principais achados de trabalhos publicados em um mesmo intervalo de tempo. No primeiro período (2000 a 2004) os pesquisadores mergulham nos temas com objetivos exploratórios analisando fatores, dimensões e diferenças. O segundo período (2005 a 2009) as pesquisas exploraram, dentre outros, temas voltados aos conteúdos gerados pelos usuários da internet (Reviews e Marketing boca a boca on-line). No terceiro período (2010 a 2014) as discussões sobre o comportamento de compra on-line são aprofundadas e o fenômeno das mídias sociais transita entre os diversos temas ligados ao comportamento de compra dos consumidores, figurando como um importante fenômeno para a compreensão comportamento dos consumidores. O último período (2015 a 2019) mostra um aprofundamento dos pesquisadores no fenômeno das mídias sociais e evidencia temas emergentes tais quais IOT, marketing digital e sustentabilidade e influenciadores digitais.

Pelas tendências evidenciadas por estas pesquisas espera-se que nos próximos anos pesquisadores aprofundem nos temas evidenciados como emergentes do último período. E explorem também as lacunas identificadas: estudos longitudinais na perspectiva empresarial e das marcas sobre os impactos do marketing boca a boca negativo e positivo, estudos transculturais que evidencie se há ou não a relação de fatores culturais na geração de reviews on-linee utilização de sites de reclamação.

Diante do exposto, evidencia-se que este estudo contribui, com um panorama geral das publicações que tiveram como discussão central a influência do marketing digital no comportamento de compra de consumidores. Evidenciando tendências, lacunas e direcionamentos para pesquisas futuras. Essa pesquisa apresenta informações valiosas à gestores de marketing, dado que compreender o comportamento de compra dos consumidores é vital para o sucesso de empresas no mercado, conforme defendem os pesquisadores Ramya e Ali (2016).

Esse estudo limitou-se apenas a artigos publicados e disponibilizados gratuitamente em 5 bases indexadoras de artigos científicos e às palavras chaves e intervalo de tempo escolhido. Sugere-se que pesquisas futuras explorem a agenda de pesquisa proposta e que as próximas revisões da literatura expandam os critérios e escolhas metodológicas adotados nesse trabalho.

\section{REFERÊNCIAS}

ALALWAN, A. A.; RANA, N. P.; DWIVEDI, Y. K.; ALGHARABAT, R. Social media in marketing: A review and analysis of the existing literature. Telematics and Informatics, v. 34, n. 7, p. 1177-1190, 2017. 
ALGHARABAT, R. S.; RANA, N. P.; ALALWAN, A. A.; BAABDULLAH, A. M. Investigating the Impact of Social Media Commerce Constructs on Social Trust and Customer Value Co-creation: A Theoretical Analysis. In: RANA, N.P. et al. (ed.) Digital and Social Media Marketing. Springer: Cham, 2020. p. 41-55.

CHIANG, I. P.; YI LIN, C.; HUANG, C. H. Measuring the Effects of Online-to-Offline Marketing. Contemporary Management Research, v. 14, n. 3, p. 167-189, 2018.

COVIELLO, N.; MILLEY, R.; MARCOLIN, B. Understanding IT-enabled interactivity in contemporary marketing. Journal of interactive marketing, v. 15, n. 4, p. 18-33, 2001.

GALVÃO, C. M.; SAWADA, N. O.; TREVISAN, M. A. Revisão sistemática: recurso que proporciona a incorporação das evidências na prática da enfermagem. Revista Latino Americana de Enfermagem, v. 12, n. 3, p. 549$565,2004$.

GOMES, C. F.; REIS, H. M. Marketing digital. Revista Interface Tecnológica, v. 12, n. 1, p. 53-62, 2015.

GONÇALVES, D. V.; KLATTE, A. D. S.; DA SILVA, G. R. M.; DA SILVA, S. M.; DA SILVEIRA, O. F. Marketing digital e sua influência atual. Revista da Mostra de Iniciação Científica e Extensão, v. 5, n. 1, 2019.

GREWAL, L.; STEPHEN, A. T. In mobile we trust: The effects of mobile versus nonmobile reviews on consumer purchase intentions. Journal of Marketing Research, v. 56, n. 5, p. 791-808, 2019.

KANNAN, P. K. Digital marketing: A framework, review and research agenda. International Journal of Research in Marketing, v. 34, n. 1, p. 22-45, 2017.

KAPLAN, Andreas M.; HAENLEIN, Michael. Users of the world, unite! The challenges and opportunities of Social Media. Business horizons, v. 53, n. 1, p. 59-68, 2010.

KUMAR, A.; BEZAWADA, R.; RISHIKA, R.; JANAKIRAMAN, R.; KANNAN, P. K. From social to sale: The effects of firm-generated content in social media on customer behavior. Journal of Marketing, v. 80, n. 1, p. 7-25, 2016.

LAZZAROTTI, F.; DALFOVO, M. S.; HOFFMANN, V. E. A bibliometric study of innovation based on Schumpeter. Journal of technology management \& innovation, v. 6, n. 4, p. 121-135, 2011.

MACHADO JUNIOR, C.; SOUZA, M. T. S.; PARISOTTO, I. R. S.; PALMISANO, A. As Leis da Bibliometria em Diferentes Bases de Dados Científicos. Revista de Ciências da Administração, v.18, n.44, p.111-123, abril 2016.

MEYER-WAARDEN, Lars; BENAVENT, Christophe. Grocery retail loyalty program effects: self-selection or purchase behavior change?. Journal of the Academy of Marketing Science, v. 37, n. 3, p. 345-358, 2009.

MOGOS, R. I. Digital Marketing for Identifying Customers' Preferences-A Solution for SMEs in Obtaining Competitive Advantages. International Journal of Economic Practices and Theories, v. 5, n. 3, p. 240-247, 2015.

MORENO, F. M.; LAFUENTE, J. G.; CARREÓN, F. Á.; MORENO, S. M. The characterization of the millennials and their buying behavior. International Journal of Marketing Studies, v. 9, n. 5, p. 135-144, 2017.

PETIT, O.; VELASCO, C.; SPENCE, C. Digital sensory marketing: Integrating new technologies into multisensory online experience. Journal of Interactive Marketing, v. 45, p. 42-61, 2019.

RAMYA, N.; ALI, M. Factors affecting consumer buying behavior. International journal of applied research, v. 2, n. 10, p. 76-80, 2016.

RYAN, D. Digital marketing: Marketing strategies for engaging the digital generation. $4^{a}$ edition. London: Kogan page LTDA, 2017. 
SHAMOUT, M. D. The impact of promotional tools on consumer buying behavior in retail market. International Journal of Business and Social Science, v. 7, n. 1, p. 75-85, 2016.

SIQUEIRA, J. P. L.; ANGELO, C. F.; ZWICKER, R. Migration of consumers to internet shopping in São Paulo. REGE - Revista de Gestão, v. 16, n. 4, p. 93, 2009.

SOUSA JÚNIOR, J. H. “Novos" consumidores, "novos" mercados: A inclusão de grupos marginalizados e seus reflexos no varejo brasileiro. $1^{\text {a }}$ ed., São Paulo: Pimenta Cultural, 2019.

SOARES, P. B.; CARNEIRO, T. C. J.; CALMON, J. L.; CASTRO, L. O. C. O. Análise bibliométrica da produção científica brasileira sobre Tecnologia de Construção e Edificações na base de dados Web of Science. Ambiente Construído, v.16, n.1, Porto Alegre, Jan./Mar., 2016.

SURYAWARDANI, I. G. A. O.; WIRANATHA, A. S. Digital Marketing in Promoting Events and Festivities. A case of Sanur Village Festival. Journal of Business on Hospitality and Tourism, v. 2, n. 1, p. 159-167, 2017.

VARADARAJAN, P. R.; YADAV, M. S. Marketing strategy and the internet: an organizing framework. Journal of the Academy of Marketing Science, v. 30, n. 4, p. 296-312, 2002.

VASCONCELOS, G. M. R. Métodos mistos e análise de relacionamentos de negócios. Revista Pretexto, v. 15, n. 3, p. 74-89, 2014.

VOLPATO, B. Marketing Digital no Brasil: Pesquisa traz dados sobre maturidade das empresas no Marketing Digital e Vendas. 2019. Disponível em: https://resultadosdigitais.com.br/blog/pesquisamaturidade-do-marketing-digital-e-vendas-no-brasil/. Acessado em: 24/04/2020

WATERLANDER, W. E.; JIANG, Y.; NGHIEM, N.; EYLES, H.; WILSON, N.; CLEGHORN, C.; BLAKELY, T. The effect of food price changes on consumer purchases: a randomised experiment. The Lancet Public Health, v. 4, n. 8, p. e394-e405, 2019.

WE ARE SOCIAL. Digital in 2020. 2020. Disponível em : <https://datareportal.com/reports/digital-2020-brazil. Acesso em: 24 abr. 2020.

WIDODO, A.; YUSIANA, R.; ANGGI, S. How E-marketing and trust influence online buying decision: A case study of mataharimall. com in Bandung. Pertanika. Journal of Social Sciences and Humanities, v. 25, p. 107$114,2017$.

XIANG, L.; ZHENG, X.; LEE, M. K.; ZHAO, D. Exploring consumers' impulse buying behavior on social commerce platform: The role of parasocial interaction. International journal of information management, v. 36, n. 3, p. 333-347, 2016.

ZHANG, K. Z.; XU, H.; ZHAO, S.; YU, Y. Online reviews and impulse buying behavior: the role of browsing and impulsiveness. Internet Research, 2018. 